\title{
Health sciences librarians in academic libraries: a brief review of their developing role
}

\author{
Maurice Wakeham
}

Faculty Liaison Librarian - Health and Social Care, Anglia Ruskin University

Maurice Wakeham, University Library, Anglia Ruskin University, Bishop Hall Lane, Chelmsford, Essex, CM11 2LT, UK. Email:

maurice.wakeham@anglia.ac.uk

Information relating to health has been gathered since ancient times. Physicians often gathered their own books which were sometimes donated to create early medical libraries. The explosion of information, the demands of qualification accrediting bodies and technological developments have also helped to promote the work of health libraries. The professionalisation of health occupations has tended to move their library support from hospitals into academic settings. Librarians are increasingly concerned with promoting their services and teaching patrons to use library resources. While some health sciences librarians see the availability of health information on the internet as a threat, to those that can see ways to exploit it, it may serve to enhance their role. 
Libraries are places, physical or virtual, where knowledge is gathered, organised and then made available to potential users. Health science libraries gather material of relevance to health service practitioners and related professionals. Some may be targeted at particular professions within that group, such as doctors or nurses, while some may also cater inclusively for a broader range of health professionals, such as radiographers, dieticians or a range of therapists and managers. Workers or volunteers in health related fields may require not only clinical or medical information but also, for example, ethical, economic, educational, psychological or management resources. Health librarians may find themselves dealing with practitioners, students, researchers and even the consumers of health service provision patients, their friends and relatives. Their roles have evolved in a number of ways to facilitate this. The library itself may be located within a hospital, a surgery, or, increasingly as far as the user is concerned, in some ethereal virtual space contactable via a keyboard. Even if not actually located within a University, and many will be, most health libraries will have organisational or managerial links with one.

This paper will seek to briefly outline the foundations of libraries that deal with medical and health materials and how they have evolved into their current academic settings. It will indicate some of the many roles, subjects and types of people that the health library worker has to deal with today (University of British Columbia 2009). 


\section{Historical context}

Human beings have always had a fundamental interest in their health. Recording details of health and ways of taking care of it have always been important. Some of the earliest gatherings of such writings have come to us, for example, in the form of clay tablets from the library of King Assurbanipal or papyri prescriptions, over 3000 years old, from the Temple of Thoth in Egypt. Copies of the writings of the early physicians such as Galen and Hippocrates were passed down via the Islamic schools and libraries of Spain and the Middle East. Over time Christian medieval monasteries, took on the roles of scribes and carers of the sick. From the thirteenth century onwards materials were gathered in the universities where medical schools were founded, such as Florence, Paris and Aberdeen. The invention of printing led to wider production of the classical texts, sometimes in Latin but also in the vernacular. Printing facilitated the rise of the scientific journal. With wider availability of information physicians and others began to discuss and exchange information through the formation of scientific societies. In London the Royal Society of Medicine Library has its roots in the $15^{\text {th }}$ century, while the Royal College of Physicians has had a library from its foundation in 1518. The Royal College of Physicians of Edinburgh Library was founded in 1682 with a donation of "three shelfes full of books".

The first working medical library in the US was founded for the staff and students of Pennsylvania Hospital in 1762. The United States National Library of Medicine (NLM), currently the world's largest medical library, was created 
in 1956 but had its roots in a small collection of books and journals in the office of the Surgeon General of the Army, enough to fill around thirty feet of shelving by 1840 . The NLM now holds over 9 million items.

The phenomenal explosion of health related information over the last century is just one of the contexts within which health libraries now operate. The evolution of libraries serving the health sector, in common with libraries in general, has seen a move from the librarian as a keeper of texts to a promoter of the use of information derived from texts. The libraries reflect the changes within society and the institutions through which health care is delivered. This development within US hospital libraries in the twentieth century was a product of the American Medical Association's requirements for improving medical schools. Health library provision in many countries has been enhanced by professional award accrediting bodies and statutory regulators recognising the importance of access to research and the body of knowledge by which diagnoses and treatments can be evidenced. The move of nursing into higher education in the UK in the 1980s brought about a qualitative improvement in information provision for the mass of nurses. It changed what libraries stocked, where they were located, the nature of the staff that ran them and how they networked with one another (Wakeham 2002). Though specialist libraries still exist, rather than providing for an elite group of surgeons and clinicians most hospital-based libraries are now multidisciplinary, serving a wide range of professions. 


\section{Networking and collaboration}

Even with such developments, or perhaps because of them, librarians are aware of the limitations of their own collections. Most general hospital libraries belong to regional networks but not all are formally linked to University libraries. They seem to have a professional desire to gather together in order to share resources and knowledge (Palmer 1994; Wakeham 2008). One of the largest groups of the UK Chartered Institute for Information Professionals (cilip) is the Health Libraries Group, which dates back under various names to 1947. This in turn now has two sub-groups - Libraries for Nursing and IFM Healthcare, the Information Management sub-group, which also provide information and development activities for their members. In the USA the Association of Medical Librarians was established in 1898 to encourage the foundation of public medical libraries, though today public libraries would only purchase general medical titles. Now called the Medical Library Association, it has 23 'sections' and 14 geographic groups. The Association of Academic Health Sciences Libraries and Libraries in Medical Education also give support to their members.

Collaborative groupings operate internationally, for example the European Association for Health Information and Libraries (EAHIL) or the Association for Health Information and Libraries in Africa (AHILA) and, since 1953, through periodic meetings of the ICML (International Congress of Medical Librarians). The World Health Organisation (WHO) has its own library and cooperates with major publishers, through the HINARI project, to provide free or low cost 
access to health related literature in the developing world. WHO also work with the IFLA (International Federation of Library Associations and Institutions) Health and Biosciences Libraries Section. Charities such as Partnerships for Health are concerned to promote the value of health libraries to people in the developing world, where such libraries, if they exist at all, are often inadequately staffed and provisioned (Walia and Chadha 2007).

\section{Developing the role}

The development of the evidence-based movement, changes in curricula and in the delivery of the education of health professionals from a didactic approach to more interactive methods such as enquiry based, or problem based learning, affects the nature of libraries. Librarians, particularly but not exclusively in academic libraries, are increasingly being called upon to develop the information literacy of students and, in an age of lifelong learning and continuing professional development, experienced practitioners and researchers (Gannon Leary et al 2003; Perry and Kronenfeld 2005). In some settings librarians, sometimes called informationists in this context, are becoming part of the clinical team, available to provide information on the ward (Davidoff and Florance 2000; Rankin et al 2008). In other cases library services provide information directly to clinicians via mobile devices like Personal Digital Assistants (PDAs) (Honeybourne et al 2006; Burnette and Dorsch 2006). Increasingly they respond directly not only to professionals but also to the needs of patients and the general public (Stahl 2001). They no longer provide just books and journals but, over the years, have adopted a 
range of new technologies. Microfiche, slides, compact discs have come, and in some libraries gone, to be replaced by electronic social networks, blogs and wikis and the world wide web (Wood 2007). The desire to provide 24 /7 support leads some to provide services which utilise the time differences around the world, such as the Chasing the Sun service (Rockliff and Peterson 2007).

Libraries contribute at a national and international level to the promotion of material. The National Library of Medicine, which has been indexing articles since the late nineteenth century, now makes its PubMed database and, through the PubMed Central service, full text articles, freely available. The work of the Cochrane collaboration, the NHS Centre for Reviews and Dissemination and the US Agency for Healthcare Research and Quality, among others, benefit from librarians' contributions to the production of systematic reviews and guidelines (McGowan and Sampson 2003). In the twenty first century UK librarians have contributed to the work of the National electronic Library for Health (NeLH) which became the National Library for Health, now absorbed by NHS Evidence. To help with sifting the morass of uncontrolled information which is the internet, librarians helped create gateways to quality sites such as the Resource Discovery Network and OMNI (Organised Medical Networked Information) and their successor, Intute.

The story of academic health sciences librarianship shares much with that of the profession in general. It reflects the democratisation of information access largely facilitated by technological change which has occurred over the last 
century. Health libraries take many forms and each must target its services at the needs of its users. The busy clinician has different needs to an enquiring student or patient. Libraries are no longer places where papyri are kept in jars on shelves. Library holdings are no longer isolated, protected by priestly guardians but may be procured regionally, nationally, or from anywhere in the world. Information must be promoted and shared with users who may need to be taught how to find and evaluate it. Health librarianship is partly to do with gathering information but is increasingly concerned with persuading users and potential users to value and enabling them to use what the library has access to.

\section{To sum up}

Health care today is often delivered by teams of professionals in a range of settings. They have a variety of needs in relation to different aspects of their role. Patients and prospective patients have ever increasing demands and expectations. The scientific, medical and basic research literature that is available grows exponentially and is no longer the exclusive preserve of the expert professional. It is the task of health librarians to manage and filter information for this range of users with multiple needs. Librarians do this as individuals or as members of teams. They may work with scientists at the forefront of research or poorly informed members of the public or both. Watstein (2004) outlines the emerging roles of health sciences librarians and their centrality to their institutional missions. In the UK and elsewhere, whether based in hospitals or higher education, health librarians are 
responding to the new challenges in similar ways. The librarian may be a mediator, a facilitator, a teacher, an advisor, a researcher or all of these. Technology has freed libraries and librarians from the constraints of place and time and changed the way everyone relates to knowledge and information. It has not yet however replaced the academic health sciences librarian. Indeed it has, and continues, to support the expansion of their role.

\section{References}

Burnette, Peg, and Jo Dorsch. "From Novelty to Necessity: Impact of PDA Experience on Medical Libraries." Reference Librarian 45.93 (2006): 8398.

Davidoff, Frank, and Valerie Florance. "The Informationist: A New Health Profession." Annals of Internal Medicine 132.12 (2000): 996-8.

Gannon-Leary, Pat, Maurice Wakeham and Graham Walton. "Making a Difference! to Nurse Education: The Impact on HE Libraries." Journal of Library and Information Science 35.1 (2003): 31-46.

Honeybourne, Claire, Sarah Sutton and Linda Ward. "Knowledge in the Palm of Your Hands: PDAs in the Clinical Setting." Health Information \& Libraries Journal 23.1 (2006): 51-9.

McGowan, Jessie, and Margaret Sampson. "Systematic Reviews Need Systematic Searchers." Journal of the Medical Library Association 93.1 (2005): 74-80. 
Palmer, Judy. "Professional Associations in Health Information." Medical Health and Welfare Libraries Group Newsletter 11 (1994): vii-xiii.

Perry, Gerald J, and Michael R Kronenfeld. "Evidence-Based Practice: A New Paradigm Brings New Opportunities for Health Sciences Librarians." Medical Reference Services Quarterly 24.4 (2005): 1-16.

Rankin, Jocelyn A, Candace C. Canto and Suzanne F. Grefsheim. "The Emerging Informationist Specialty: A Systematic Review of the Literature." Journal of the Medical Library Association. 96.3 (2008): 194206.

Rockliff, Sue, and Mary Peterson. "Chasing the Sun: the story so far." 2007 Powerpoint presentation.

<http://www.alia.org.au/groups/healthnat/hla.symposium/chasing.sun.liffe. ppt\#277,23, Chasing the Sun: the story so far>.

Stahl, Linda M. "Providing Meaningful Patient Information." Journal of Hospital Librarianship 1.4 (2001): 53-61.

University of British Columbia. "UBC Health Libraries Wiki." UBC. 17th June 2009 2009. <http://hlwiki.slais.ubc.ca/index.php/UBC HealthLib-Wiki A Knowledge-Base for Health Librarians>.

Wakeham, Maurice. "From Locked Cupboard to University Library: Libraries for Nurses in the UK After 1955." Library History 18.1 (2002): 39-60. 
---. "From UHSL to UHMLG: The Evolution of a Group for Health Librarians in Higher Education." Health Information \& Libraries Journal 25.4 (2008): 270-7.

Walia, P.K. and Chhaya Chadha. "Current Status of Health Sciences Libraries in Delhi: A Study." Journal of Library \& Information Science 32.1 (2007): 73-84.

Watstein, S B "Emerging roles of health sciences librarians: academic library centrality" Reference Services Review 32.1 (2004): 13-15.

Wood, M. Sandra, ed. Medical Librarian 2.0: Use of Web 2.0 Technologies in Reference Services. Binghamton, N.Y.: Haworth Press, 2007. 